\title{
AUDIT TATA KELOLA SENAYAN LIBRARY MANAGEMENT SYSTEM (SLIMS) MENGGUNAKAN FRAMEWORK COBIT 5.0
}

\author{
Ferly Ardhy ${ }^{1}$ Asep Afandi ${ }^{2}$ Septi Nur Handayani ${ }^{3}$ \\ Sistem Informasi ${ }^{123}$ \\ STMIK Dian Cipta Cendikia Kotabumi ${ }^{123}$ \\ Jalan Negara No.03 Candimas, Lampung Utara \\ E-mail : ferly@dcc.ac.id ${ }^{1}$, asefafandi189@gmail.com ${ }^{2}$, septygeegee@gmail.com ${ }^{3}$
}

\begin{abstract}
Abstrak
Senayan Library Management System (SLiMS) adalah Open Source perangkat lunak sistem manajemen perpustakaan (library management system) berbasis web. Tata Kelola SLiMS memerlukan kegiatan audit untuk mengukur Capability Leve lsaat ini dan memberikan rekomendasi untuk proses perbaikan untuk masa yang akan dating pada Perpustakaan SMAN 1 Abung Semuli.
\end{abstract}

Metode yang yaitu Framework COBIT 5.0 karena berfokus pada sasaran bisnis dan merupakan alat manajerial dant eknikal.Audit yang dilakukan untuk Tata Kelola SLiMS ini berfokus pada Domain Process EDM2, EDM3, APO4, BAI2, DSS4 dan MEA1.

Hasil pengukuran bernilai 2,54 dikarenakan index pembulatan nilai maka hasil berada di level 3 (Established Process) yaitu saat ini proses tata kelola pada setiap Domain Process telah terdefinisi dan terstandarisasi dengan baik sehingga system SLiMS stabil untuk di implementasikan, sedangkan level yang diharapkan berada pada level 4 sehingga terjadi Gap sebesar 1,45. Untuk dapat mengatasi Gap yang ada, maka dibuatlah sebuah rekomendasi yaitu agar memaksimalkan keselarasan SOP Tata Kelola Perpustakaan dengan kebijakan yang berlaku.

Kata kunci :SLiMS, Framework COBIT 5.0, Capability Level.

Abstrak

Senayan Library Management System (SLiMS) is a web-based Open Source library management system software. SLiMS Governance requires an audit activity to measure the current Capability Leve and provide recommendations for the improvement process for the future in the SMAN 1 Abung Semuli Library.

The method is COBIT 5.0 Framework because it focuses on business goals and is a technical and managerial tool. The audit conducted for SLiMS Governance focuses on Domain Processes EDM2, EDM3, APO4, BAI2, DSS4 and MEA1.

The measurement results are 2.54 due to the rounding index value, the results are at level 3 (Established Process), which is that the governance process at each Domain Process has been well defined and standardized so that the SLiMS system is stable to be implemented, while the expected level is at level 4 so that a gap of 1.45 occurs. To be able to overcome the existing gap, a recommendation is made to maximize the alignment of the Library Governance SOP with the applicable policies.

Keywords: SLiMS, Framework COBIT 5.0, Capability Level.

\section{PENDAHULUAN}

Perpustakaan adalah unit pelaksana teknis yang bertugas menyediakan dan mendayagunakan bahan pustaka, melakukan pelayanan referensi, dan memelihara bahan pustaka dan melakukan tata usaha perpustakaan. Perpustakaan sebagai pusat pengumpulan informasi, Perpustakaan sebagai pengolahan informasi, Perpustakaan sebagai pelestarian informasi, Perpustakaan sebagai penyediaan pemanfaatan informasi, dan Perpustakaan sebagai penyebarluasan informasi yang relevan sebagai sumber literatur bagi suatu 
penelitian. Tujuan pelaksanaan audit adalah Untuk mengetahui sejauh mana capability level Tata Kelola SLiMS di SMAN 1 Abung Semuli menggunakan framework COBIT 5.0 domain EDM2, EDM3, APO4, BAI2, DSS4, dan MEA1 serta memberikan rekomendasi untuk proses perbaikan agar mencapai target Capability Level yang di harapkan SMAN 1 Abung Semuli sesuai dengan hasil pengisian kuesioner.

\section{METODE PENELITIAN}

Dalam penelitian kali ini peneliti menggunakan metode pengumpulan data baik data yang bersifat kualitatif dan juga kuantitatif. Berikut ini adalah alur penelitian yang di gunak

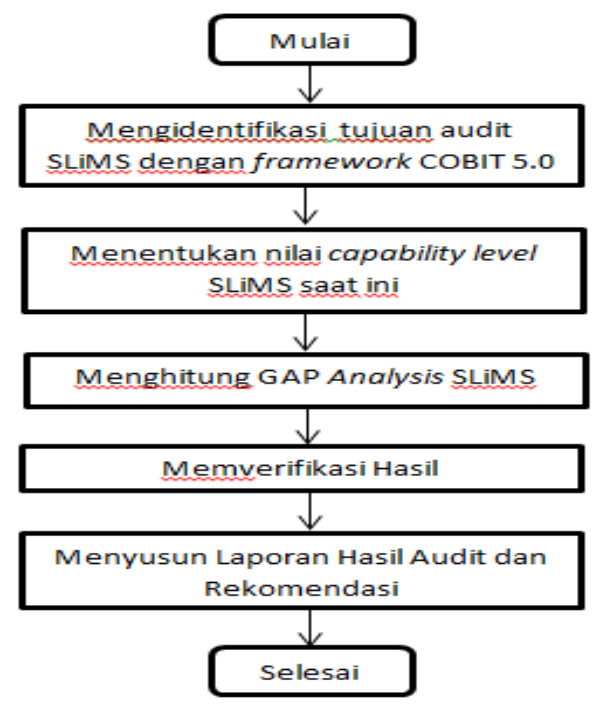

Gambar 1. Alur Penelitian Audit

Selain itu juga peneliti menggunakan metode Cobit 5.0 untuk mengetahui dan mengidentifikasi kebutuhan domain yang di butuhkan pada saat melalakukan audit.

\subsection{Tata Kelola}

Tata kelola adalah rangkaian proses, kebiasaan, kebijakan, aturan, dan institusi yang mempengaruhi pengarahan, pengelolaan, serta pengontrolan suatu perusahaan. Tata kelola organisasi juga mencakup hubungan antara para stakeholder yang terlibat serta tujuan pengelolaan organisasi. Pihak-pihak utama dalam tata kelola organisasi atau perusahaan adalah pemegang saham (stakeholder), manajemen, dan dewan direksi. Stakeholder lainnya termasuk karyawan atau staff, pemasok (supplier), pelanggan (customer), pihak ketiga seperti bank, kreditor, dan organisasi lain yang berhubungan, regulator, lingkungan, serta masyarakat luas ${ }^{1}$ (Agustin dan Holil, 2015).

\subsection{COBIT (Control Objectives for Information and Related Technology)}

COBIT adalah kerangka IT governance yang ditujukan kepada manajemen, staf pelayanan IT, control departement, fungsi audit dan lebih penting lagi bagi pemilik proses bisnis (business process owners), untuk memastikan confidentiality, integrity, dan availability data serta informasi sensitif dan kritikal ${ }^{2}$ (Fransiskus, 2016). COBIT 5.0 (ISACA, 2017d) membagi proses tata kelola dan manajemen IT perusahaan menjadi dua area proses utama:

a. Tata kelola (Govermance), yang memuat lima proses tata kelola, dimana akan ditentukan praktek-praktek dalam setiap proses Evaluate, Direct, dan Monitor (EDM).

b. Manajemen, memuat empat domain, sejajar dengan area tanggung jawab dari Plan, Build, Run, and Monitor (PBRM), dan menyediakan ruang lingkup IT yang menyeluruh. Domain ini merupakan evolusi dari domain dan struktur proses dalam 4.1, yaitu Align, Plan, and Organize (APO), Build, Acquare, and Implement (BAI), Deliver, Service and Support 
(DSS), Monitor, Evaluate, and Assess (MEA).

Pada framework COBIT 5 yang dikeluarkan oleh ISACA (2017), tidak lagi menggunakan Maturity Level seperti pada COBIT 4.1 (2007) sebelumnya. Maturity Level diganti menjadi Process Capability Level yang diadopsi dari ISO/IEC 155042, dimana proses penilaian akan berdasarkan tingkat kemampuan sebuah organisasi dalam melakukan proses-proses yang telah didefinisikan dalam model assesment.

Berikut ini tabel skala pembulatan index yang di gunakan untuk menentukan tingkat Process Capability Level :

Tabel 1 Skala Pembulatan Index

\begin{tabular}{|c|l|}
\hline & \\
\hline evel Pembulatan & gkat Model Capability \\
\hline $4.51-5.00$ & Optimising Process \\
\hline $3.51-4.50$ & Predictable Process \\
\hline $2.51-3.50$ & Established Process \\
\hline $1.51-2.50$ & Managed Process \\
\hline $0.51-1.50$ & Performed Process \\
\hline $0.00-0.50$ & Incomplete Process \\
\hline
\end{tabular}

\section{HASIL DAN PEMBAHASAN}

Kuesioner merupakan daftar pernyataan yang disiapkan oleh peneliti yang dimana tiap pernyataan berkaitan dengan masalah penelitian. Kuesioner pada penelitian ini dirancang untuk mengetahui capability level tata kelola SliMS yang telah diterapkan di Perpustakaan SMAN 1 Abung Semuli untuk mengetahui tanggapan pengguna sistem dan untuk pembuatan saran tata kelola sistem melalui perbandingan antara kondisi saat ini dengan harapan ataupun rekomendasi perbaikan untuk kedepannya. Pernyataan dibuat berdasar pada Framework COBIT 5.0 fokus pada domain EDM2, EDM3, APO4, BAI2, DSS4, dan MEA1 yang mana kuesioner ini akan dibagikan dan diisi oleh 80 responden yang terdiri dari Kepala Sekolah, Kepala Perpustakaan, Semua staff pengelola SliMS, beberapa dewan guru dan siswa-siswi SMA Negeri 1 Abung Semuli. Berikut adalah draft kuisioner yang akan di isi oleh 80 responden :

1.MEA1 Monitor, Evaluate and Assess Performance and Conformance (Memantau, Mengevaluasi, dan Menilai Kinerja dan Penyesuaian)

Tabel 2 Kuesioner Pernyataan MEA1

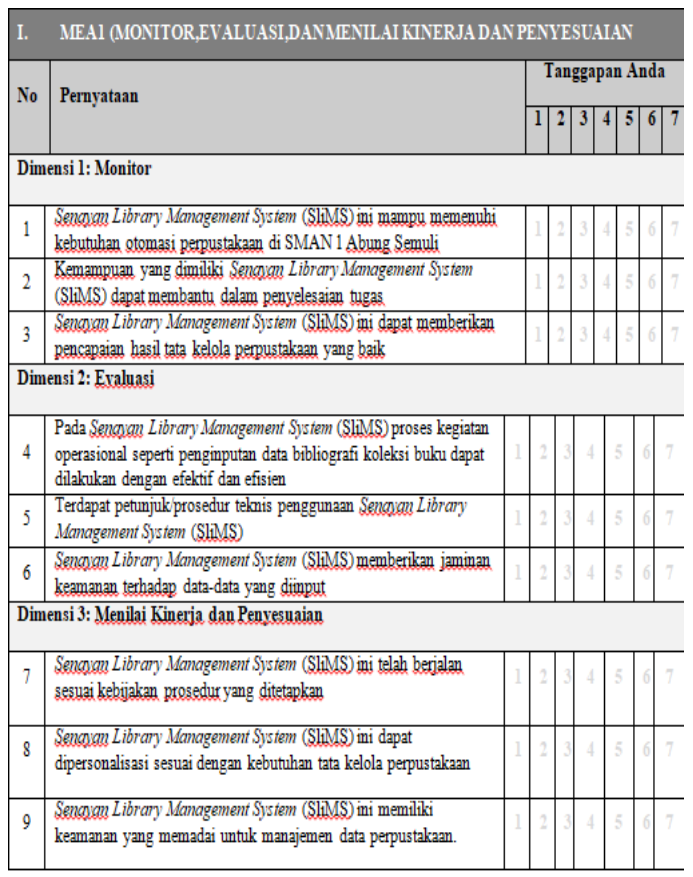


2. EDM2 Ensure Benefits Delivery (Memastikan Penyampaian Manfaat)

Tabel 3 Kuesioner Pernyataan EDM2

\begin{tabular}{|c|c|c|}
\hline \multicolumn{3}{|c|}{ II. EDM2 (MEMASTIKAN PENYYAIPAIANMANFAAT) } \\
\hline \multirow{2}{*}{$\mathrm{N}$} & \multirow{2}{*}{ Perny̧atan } & Tanggapan Anda \\
\hline & & \begin{tabular}{l:l|l|l|l|l}
1 & 2 & 3 & 4 & 5 & 6
\end{tabular} \\
\hline 10 & 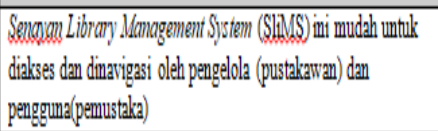 & \\
\hline 11 & 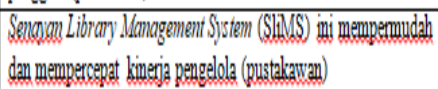 & \\
\hline 12 & 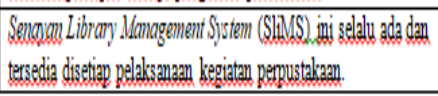 & \\
\hline
\end{tabular}

3. EDM3 Ensure Risk Optimisation

(Memastikan Pengoptimalan Resiko)

Tabel 4 Kuesioner Pernyataan EDM3

\begin{tabular}{|c|c|c|c|}
\hline \multicolumn{4}{|c|}{ III EDMB (MENASTIKAN PENGOPTIMALANRESTKO) } \\
\hline \multirow{2}{*}{$\mathrm{N}_{0}$} & \multirow{2}{*}{ Pernyatanan } & \multicolumn{2}{|c|}{ Tanggapan Anda } \\
\hline & & $1: 2: 3 \cdot 4$ & 56 \\
\hline 13 & 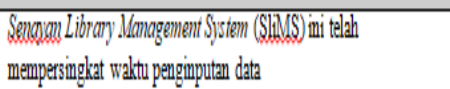 & & \\
\hline 14 & 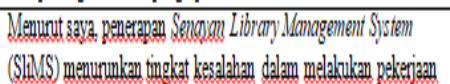 & & \\
\hline 15 & 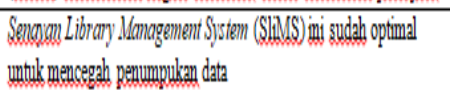 & & \\
\hline
\end{tabular}

4. APO4 Manage Innovation (Mengelola Perubahan)

Tabel 5 Kuesioner Pernyataan APO4

\begin{tabular}{|c|c|c|c|}
\hline \multicolumn{4}{|c|}{ IV AP04 (MENGELOLA PERUBAHAN) } \\
\hline \multirow{2}{*}{$N_{0}$} & \multirow{2}{*}{ Pernyataan } & \multicolumn{2}{|c|}{ Tanggapan Anda } \\
\hline & & 12 & \begin{tabular}{|l|l|l|}
4 & 56 \\
\end{tabular} \\
\hline 16 & 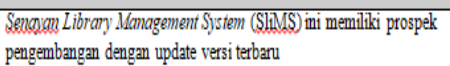 & & \\
\hline 17 & 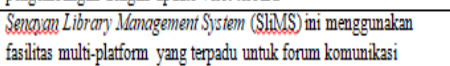 & & \\
\hline 18 & 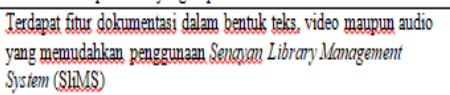 & & \\
\hline 19 & 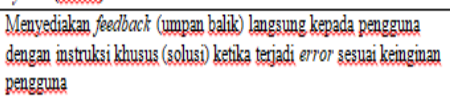 & & \\
\hline 20 & 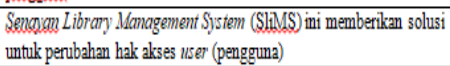 & & \\
\hline
\end{tabular}

5. BAI2 Manage Requirements Definition (Mengelola Kebutuhan)

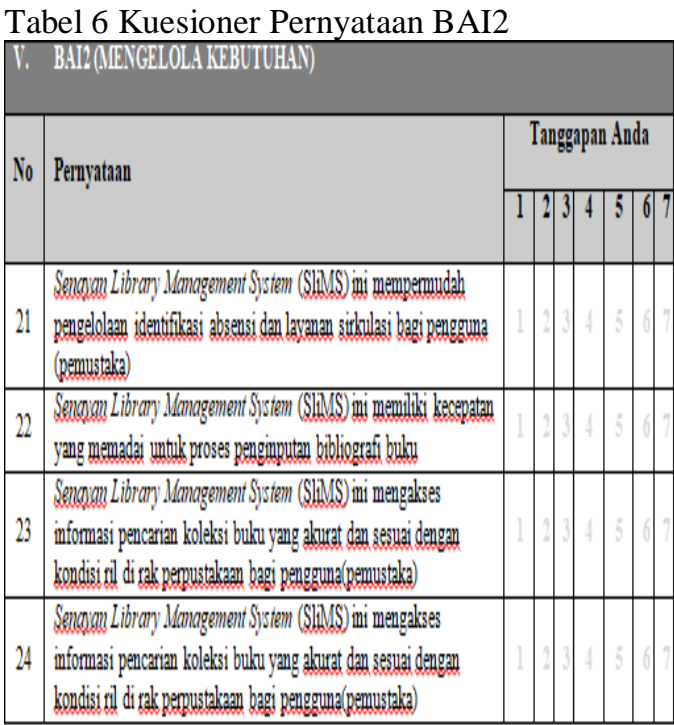

6. DSS4 Manage Continuity (Mengelola Keberlangsungan)

Tabel 7 Kuesioner Pernyataan DSS4

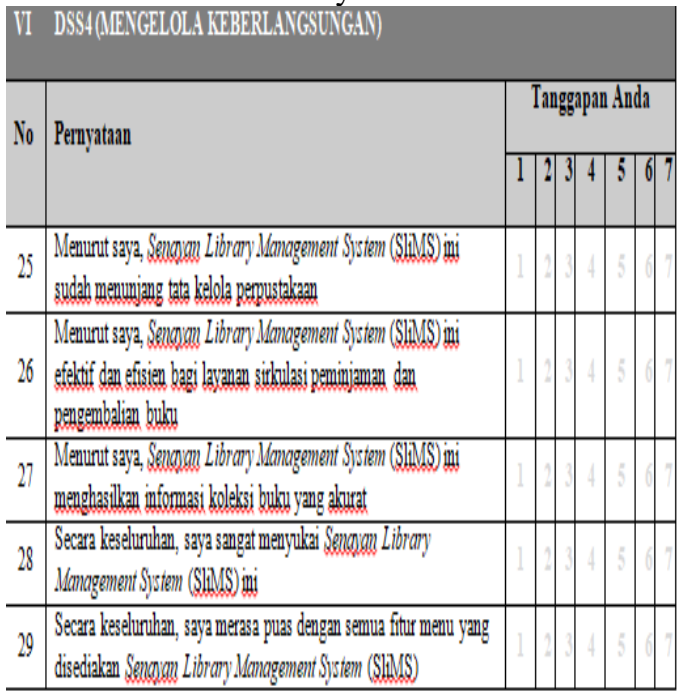

Berikut ini tabel tingkatan Proses Capability Level yang dimiliki organisasi.

Tabel 7. Level Pembulatan Index

\begin{tabular}{|c|c|}
\hline $\begin{array}{c}\text { Level } \\
\text { Pembulatan }\end{array}$ & $\begin{array}{c}\text { Tingkat Model } \\
\text { Capability }\end{array}$ \\
\hline $4.51-5.00$ & 5 - Optimising Process \\
\hline $3.51-4.50$ & $4-$ Predictable Process \\
\hline $2.51-3.50$ & 3 - Established Process \\
\hline $1.51-2.50$ & 2 - Managed Process \\
\hline
\end{tabular}




\begin{tabular}{|l|l|}
\hline $0.51-1.50$ & 1 - Performed Process \\
\hline $0.00-0.50$ & 0 - Incomplete Process \\
\hline
\end{tabular}

Tabel 8. Capability Level Domain Process MEA1

\begin{tabular}{|l|l|l|}
\hline Sub Domain & Level & Target \\
\hline MEA1.01 & 3 & 4 \\
\hline MEA1.02 & 2 & 4 \\
\hline MEA1.03 & 3 & 4 \\
\hline MEA1.04 & 2 & 4 \\
\hline MEA1.05 & 3 & 4 \\
\hline MEA1.06 & 2 & 4 \\
\hline MEA1.07 & 2 & 4 \\
\hline MEA1.08 & 3 & 4 \\
\hline MEA1.09 & 2 & 4 \\
\hline Rata-Rata & 2.444444444 & \\
\hline
\end{tabular}

Dari perhitungan capability level di dapat nilai rata-rata 2,4 (Managed Process) untuk domain MEA1, jadi dapat di simpulkan bahwa kemampuan tata kelola SLiMS sudah dikelola dengan baik pada perpustakaan SMAN 1 Abung Semuli. Sehingga didapatkan grafik di bawah ini:

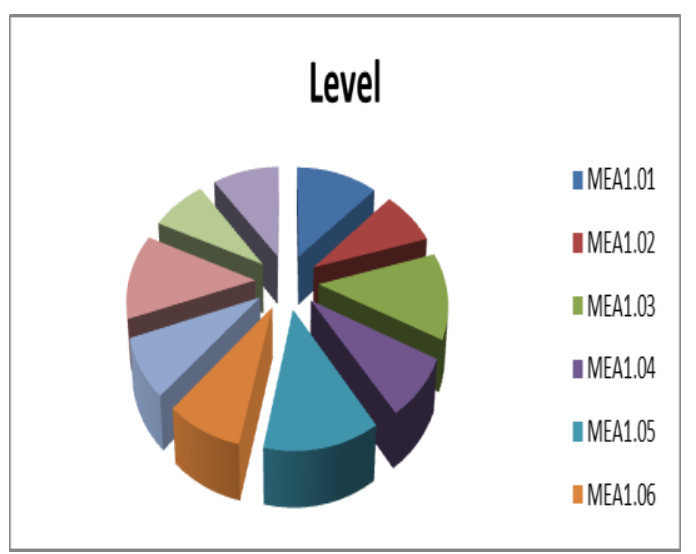

Gambar 2 Capability Level Domain Process MEA1
Tabel 8. Capability Level Domain Process EDM2

\begin{tabular}{|l|l|l|}
\hline Sub Domain & Level & Target \\
\hline EDM2.01 & 2 & 4 \\
\hline EDM2.02 & 3 & 4 \\
\hline EDM2.03 & 3 & 4 \\
\hline Rata-Rata & 2.666666667 & \\
\hline
\end{tabular}

Dari perhitungan capability level di dapat nilai rata-rata 2,6 (Established Process) untuk domain EDM2, jadi dapat di simpulkan bahwa kemampuan sistem SLiMS sudah layak di implementasikan pada perpustakaan SMAN 1 Abung Semuli. Sehingga didapatkan grafik di bawah ini:

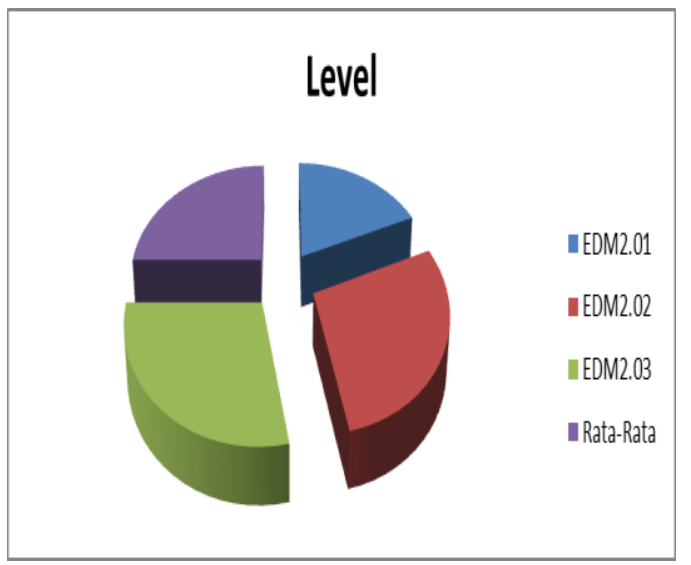

Gambar 3 Capability Level Domain Process EDM2

Tabel 9. Capability Level Domain Process EDM3

\begin{tabular}{|l|l|l|}
\hline Sub Domain & Level & Target \\
\hline EDM3.01 & 2 & 4 \\
\hline EDM3.02 & 3 & 4 \\
\hline EDM3.03 & 2 & 4 \\
\hline Rata-Rata & 2.333333333 & \\
\hline
\end{tabular}

Dari perhitungan capability level di dapat nilai rata-rata 2,3 (Managed Process) untuk domain 
EDM3, jadi dapat di simpulkan bahwa kemampuan tata kelola SLiMS sudah dikelola dengan baik pada perpustakaan SMAN 1 Abung Semuli. Sehingga didapatkan grafik di bawah ini:

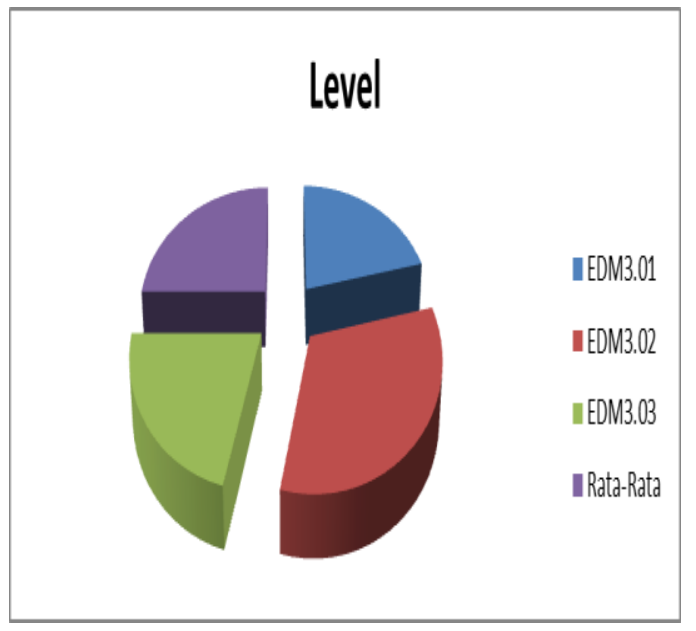

Gambar 4 Capability Level Domain Process EDM3

Tabel 10. Capability Level Domain Process APO4

\begin{tabular}{|l|l|l|}
\hline Sub Domain & Level & Target \\
\hline APO4.01 & 3 & 4 \\
\hline APO4.02 & 2 & 4 \\
\hline APO4.03 & 2 & 4 \\
\hline APO4.04 & 3 & 4 \\
\hline APO4.05 & 2 & 4 \\
\hline Rata-Rata & 2.4 & \\
\hline
\end{tabular}

Dari perhitungan capability level di dapat nilai rata-rata 2,4 (Managed Process) untuk domain APO4, jadi dapat di simpulkan bahwa kemampuan sistem SLiMS sudah layak di implementasikan pada perpustakaan SMAN 1 Abung Semuli. Sehingga didapatkan grafik di bawah ini:

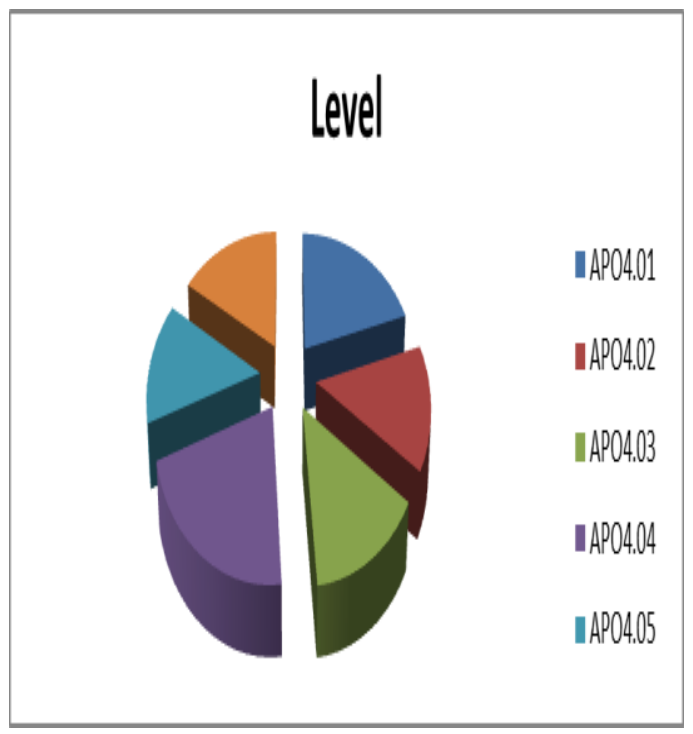

Gambar 5 Capability Level Domain Process

APO4

Tabel 11. Capability Level Domain Process BAI2

\begin{tabular}{|l|l|l|}
\hline Sub Domain & Level & Target \\
\hline BAI2.01 & 3 & 4 \\
\hline BAI2.02 & 3 & 4 \\
\hline BAI2.03 & 3 & 4 \\
\hline BAI2.04 & 3 & 4 \\
\hline Rata-Rata & 3 & \\
\hline
\end{tabular}

Dari perhitungan capability level di dapat nilai rata-rata 3 (Established Process) untuk domain BAI2, jadi dapat di simpulkan bahwa kemampuan sistem SLiMS sudah layak di implementasikan pada perpustakaan SMAN 1 Abung Semuli. Sehingga didapatkan grafik di bawah ini: 


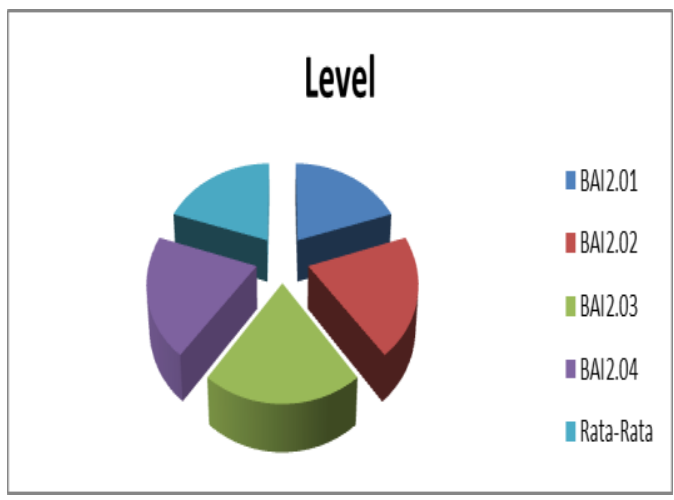

Gambar 6 Capability Level Domain

Process BAI2

Tabel 12. Capability Level Domain Process DSS4

\begin{tabular}{|l|l|l|}
\hline Sub Domain & Level & Target \\
\hline DSS4.01 & 2 & 4 \\
\hline DSS4.02 & 3 & 4 \\
\hline DSS4.03 & 2 & 4 \\
\hline DSS4.04 & 3 & 4 \\
\hline DSS4.05 & 2 & 4 \\
\hline Rata-Rata & 2.4 & \\
\hline
\end{tabular}

Dari perhitungan capability level di dapat nilai rata-rata 2,4 (Managed Process) untuk domain DSS4, jadi dapat di simpulkan bahwa kemampuan sistem SLiMS sudah layak di implementasikan pada perpustakaan SMAN 1 Abung Semuli. Sehingga didapatkan grafik di bawah ini:

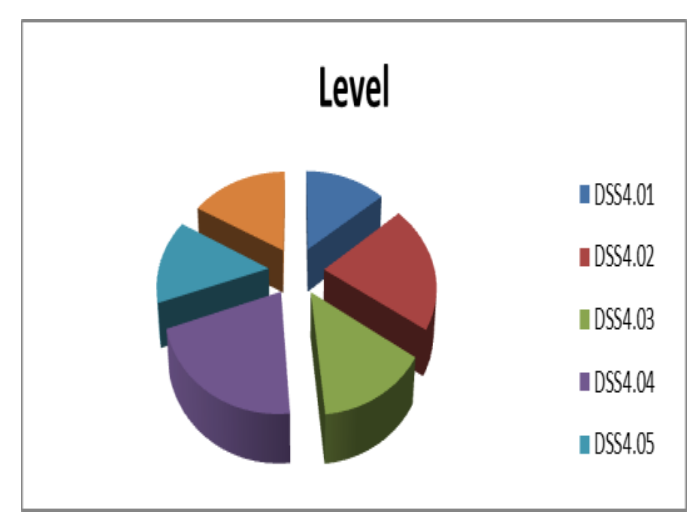

Gambar 7 Capability Level Domain Process DSS4

Tabel 13. GAP Analysis Capability Level

\begin{tabular}{|l|l|l|l|}
\hline Domain & $\begin{array}{l}\text { Capability } \\
\text { Level }\end{array}$ & Target & GAP \\
\hline MEA1 & 2.444444444 & 4 & 1.55556 \\
\hline EDM2 & 2.666666667 & 4 & 1.33333 \\
\hline EDM3 & 2.333333333 & 4 & 1.66667 \\
\hline APO4 & 2.4 & 4 & 1.6 \\
\hline BAI2 & 3 & 4 & 1 \\
\hline DSS4 & 2.4 & 4 & 1.6 \\
\hline $\begin{array}{l}\text { Rata- } \\
\text { Rata }\end{array}$ & 2.540740741 & 4 & 1.45926 \\
\hline
\end{tabular}

Dari keseluruhan perhitungan pada semua domain rata-rata yang dihasilkan untuk Capability Level yaitu 2,54 (Established Process). Jadi dapat disimpulkan bahwa kemampuan sistem SLiMS sudah stabil untuk di implementasikan pada perpustakaan SMAN 1 Abung Semuli. Sehingga didapatkan grafik untuk GAP Analysis Capability Level sebagai berikut:

\section{GAP Analysis Capability Level}

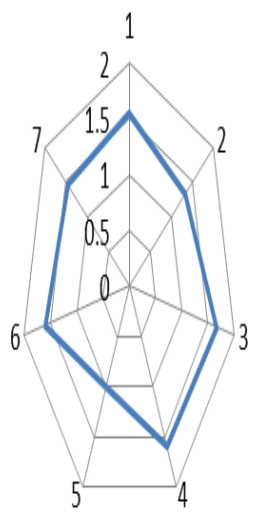

-GAP Analysis

Capability Level

Gambar 8 Grafik Proses Capability Level 


\section{PENUTUP}

Setelah penulis melakukan penelitian Audit Tata Kelola Senayan Library Management System (SLiMS) Menggunakan Framework COBIT 5.0 ( Studi Kasus : SMAN 1 Abung Semuli) telah menghasilkan beberapa kesimpulan :

1. Hasil tingkat kemampuan (Capabilty Level) Tata Kelola SLiMS berada di level 3 (Established Process) dengan rata-rata nilai 2.54 yang artinya saat ini proses tata kelola pada setiap Domain Process telah terdefinisi dan terstandarisasi dengan baik sehingga sistem SLiMS stabil untuk di implementasikan di Perpustakaan SMAN 1 Abung Semuli. Hasil ini didapatkan dari perincian pada setiap Domain Process, yaitu:

a. Pada hasil dari perhitungan kuesioner untuk Domain Process MEA1 Monitor, Evaluate and Assess Performance and Conformance (Memantau, Mengevaluasi, dan Menilai Kinerja dan Penyesuaian) rata-rata nya 5 (cenderung setuju), yaitu Capability Level saat ini berada pada level 2 dengan nilai Capability 2.4 (Managed process)

b. Pada hasil dari perhitungan kuesioner untuk EDM2 Ensure Benefits Delivery (Memastikan Penyampaian Manfaat) rata-rata nya 5 (cenderung setuju), yaitu Capability Level saat ini berada pada level 3 dengan nilai Capability 2.6 (Established Process).

c. Pada hasil dari perhitungan kuesioner untuk EDM3 Ensure Risk Optimisation (Memastikan Pengoptimalan Resiko) rata-rata nya 4 (netral), yaitu Capability Level saat ini berada pada level 2 dengan nilai Capability 2.3 (Managed process).

d. Pada hasil dari perhitungan kuesioner untuk APO4 Manage Innovation (Mengelola
Perubahan) rata-rata nya 4 (netral), yaitu Capability Level saat ini berada pada level 2 dengan nilai Capability 2.4 (Managed process).

e. Pada hasil dari perhitungan kuesioner untuk BAI2 Manage Requirements Definition (Mengelola Kebutuhan) rata-rata nya 5 (cenderung setuju), yaitu Capability Level saat ini berada pada level 3 dengan nilai Capability 3 (Established Process).

f. Pada hasil dari perhitungan kuesioner untuk DSS4 Manage Continuity (Mengelola Keberlangsungan) rata-rata nya 5 (cenderung setuju), yaitu Capability Level saat ini berada pada level 2 dengan nilai Capability 2.4 (Managed process).

2. Berdasarkan hasil perhitungan Capability level Tata Kelola SLiMS saat ini adalah 2.54. Sedangkan target Capability Level yang diharapkan adalah 4.00 maka terdapat Gap sebesar 1,45. Untuk dapat mengatasi Gap yang ada, maka dibuatlah sebuah rekomendasi agar target pencapaian Capability Level dapat mencapai level 4.

\section{DAFTAR PUSTAKA}

[1] Adikara, Fransiskus, dkk. 2016. Analisis kebutuhan stakeholder dalam rangka mengembangkan model tata kelola teknologi informasi dengan kerangka kerja COBIT 5 pada perguruan tinggi. Jakarta: Universitas Esa Unggul

[2] Agustin, Luci K., dan Holil Noor Ali. 2015. Tata Kelola Infrastruktur TI dan Non TI pada Kelas di Jurusan Sistem Informasi ITS. Surabaya: Jurnal Teknik POMITS Vol.1 No.1

[3] Astuti, Deni E. 2011. Pemanfaatan Software SLIMS (Senayan Library Management System) Dalam Pelayanan Sirkulasi Di Perpustakaan STIKES Aisyiyah 
Surakarta. Surakarta: Digital Library Universitas Sebelas Maret Surakarta

[4] Azwar, Muhammad. 2013. Membangun Sistem Otomasi Perpustakaan Dengan Senayan Library Management System (SLIMS). Gowa: Jurnal Khizanah AlHikmah Vol. 1

[5] Dwi Putri, Y.D. 2018. Audit Manajemen Teknologi Informasi Pada PT. Suri Tani Pemuka Menggunakan Framework COBIT 5. Lampung: Digital Library UNILA

[6] Fahrullah. dan Agushinta, D. 2018. Audit Sistem Informasi Perpustakaan Universitas Muhammadiyah Kalimantan Timur Menggunakan Framework COBIT 5. Tasikmalaya: LPPM STMIK DCI

[7] Fitrianingsih, N.R. 2016. Audit Digital Library UIN Sunan Kalijaga Yogyakarta Menggunakan Framework COBIT 5. Yogyakarta: Digital Library UIN Sunan Kalijaga

[8] ISACA. 2017a. COBIT 5 Enabling Process. United States: ISACA

[9] ISACA. 2017c. COBIT 5 Process Assessment Model (PAM). United States: ISACA

[10] ISACA. 2017d. COBIT 5: A Business Framework for Governance \& Management IT. United States: ISACA

[11] Nurmayanti, Nurmayanti. "Pemanfaatan Enterprise Architecture Planning Untuk Perencanaan Strategis Sistem Informasi Akademik Pada Amik Dian Cipta Cendikia Pringsewu." Jurnal Informasi dan Komputer 5.1 (2017): 1-15. [12] Romney, Marshall B., dan Paul John Steinbart. 2015. Accounting Information System. England: Pearson Educational Limited

[13] Ardhy, Ferly. "IS/IT Strategic Planning At STMIK Dian Cipta Cendikia Kotabumi." IJISCS (International Journal Of Information System and Computer Science) 2.1 (2018): 44-50.
[14] Setiani, Lana. 2018. Audit Sistem Informasi Sistem Laporan Absensi Pegawai (SILAP) Menggunakan Framework COBIT 4.1 (Study Kasus: Kantor Pelayanan Pembendaharaan Negara (KPPN) Kotabumi. Lampung: STMIK DCC Kotabumi

[15] Swastika, I Putu Agus. 2016. Audit Sistem Informasi dan Tata Kelola Teknologi Informasi: Implementasi dan Studi Kasus. Yogyakarta: Andi 
